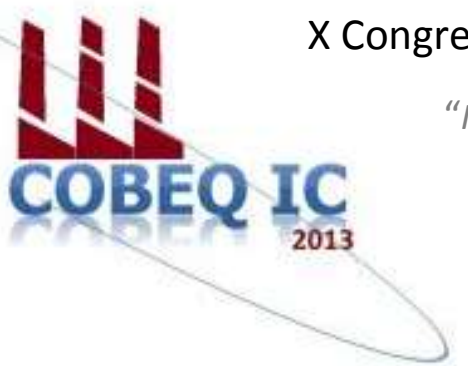

"Influência da pesquisa em Engenharia Química no desenvolvimento tecnológico e industrial brasileiro"

Universidade Federal Rural do Rio de Janeiro Universidade Severino Sombra Vassouras - RJ-Brasil

\title{
CARACTERIZAÇÃO DA MACRÓFITA AQUÁTICA Salvinia cucullata EMPREGADA NA BIOADSORÇÃO DO CORANTE SINTÉTICO ÁCIDO LARANJA 7
}

\author{
PELOSI $^{1 *}$, B. T.; LIMA ${ }^{2}$, L. K. S.; VIEIRA ${ }^{3}$, M.G.A \\ ${ }^{1}$ Graduando - FEQ/UNICAMP; ${ }^{2}$ Doutoranda - FEQ/UNICAMP \\ ${ }^{3}$ Docente - DDPP/FEQ/UNICAMP \\ Faculdade de Engenharia Química - Universidade Estadual de Campinas \\ Cidade Universitária "Zeferino Vaz”, Av. Albert Einstein, 500 - Campinas, SP - CEP: 13083-852 \\ email: melissagav@feq.unicamp.br
}

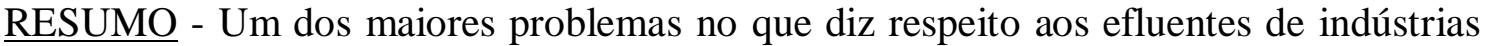
têxteis é a presença de traços de corantes que não se aderem às fibras dos tecidos durante o tingimento. Além de serem prejudiciais ao meio ambiente devido à toxidade, os corantes impedem a passagem da luz solar nos leitos de água, reduzindo a atividade fotossintética dos ambientes contaminados. Técnicas tradicionais de tratamento promovem remoção incompleta do corante e requerem altos investimentos em equipamentos, reagentes e energia. A adsorção utilizando carvão ativado, apesar de eficiente, possui desvantagens financeiras, devido ao alto custo deste material adsorvente. Assim, há uma vasta procura por biomateriais, tais como as macrófitas, que são associadas à capacidade de purificação das águas onde estão presentes atuando como bioadsorventes de poluentes convencionais, metais pesados e compostos orgânicos. Estudou-se a utilização da macrófita aquática Salvinia cucullata como bioadsorvente para a remoção do corante sintético Ácido Laranja 7. Caracterizou-se a macrófita antes e após a bioadsorção por meio de espectroscopia no infravermelho, microscopia óptica e microscopia eletrônica de varredura, além de titração potenciométrica, análise termogravimétrica e calorimetria exploratória diferencial. Após o estudo, certificou-se que a biomassa constitui um promissor bioadsorvente para o tratamento de efluentes de indústrias têxteis.
\end{abstract}

Palavras chave: efluentes, têxtil, bioadsorvente.

\section{INTRODUÇÃO}

Boa parte dos setores industriais (têxtil, papel, plástico, couro, alimentícia etc.) utilizam corantes e pigmentos em seus processos. O processo de tingimento no setor têxtil requer a utilização de grandes quantidades de água, corantes e produtos de diferentes composições (antiespumantes, dispersantes, eletrólitos, etc). Estima-se que sejam perdidos, durante a síntese e o processamento, aproximadamente $15 \%$ da produção total de corantes e pigmentos. Isto corresponde a uma descarga média diária de 128 toneladas para o meio ambiente (Zollinger, 2003). Cerca de 20\% do total de 
corantes consumidos são descartados como efluentes, devido, em especial, à fixação incompleta dos corantes às fibras no processo de tingimento. Um grande problema com a poluição por corantes é que a presença de quantidades traço destes poluentes em efluentes (menor que $1 \mathrm{ppm}$ para alguns corantes) é facilmente visível e indesejável (Robinson et al., 2001). Os efluentes de corantes, quando não tratados, exercem grandes riscos ambientais, especialmente para a saúde humana devido às suas propriedades carcinogênicas e mutagênicas (Guarantini e Zanoni, 2000). Além disso, a pigmentação afeta a qualidade da água e inibe a penetração da luz solar na cadeia aquática, reduzindo a atividade fotossintética (Sivaraj et al., 2001).

Tecnologias de tratamento de águas residuais tradicionais são ineficazes para o tratamento de efluentes contendo corantes têxteis sintéticos, por causa da estabilidade química destes poluentes (Forgacs et al., 2004). A adsorção tem se mostrado superior aos demais métodos físico-químicos usualmente empregados no tratamento de efluentes contaminados com corantes nãobiodegradéveis, em termos de custo, simplicidade de projeto, facilidade de operação e alta eficiência. $O$ carvão ativado é o adsorvente mais comumente empregado, mas seu alto custo representa uma desvantagem para seu uso em grande escala. Portanto, muitos estudos tem se focado na busca de materiais alternativos de baixo custo e eficientes como argilas (da Silva et al., 2010), turfa (Sepulveda e Santana, 2010), quitina, bagaço, cascas, leveduras, e algas (Tubiak et al., 2010). As macrófitas também são biomateriais promissores para o tratamento de efluentes contaminados com corantes, pois apresentam adaptações que permitem seu crescimento em um amplo espectro ambiental que compreende desde solos saturados até submersos na coluna d'água (Camargo et al., 2003), além de serem associadas com a capacidade de purificação de água, onde estão presentes. Podem agir como bioadsorventes de poluentes convencionais, metais pesados e compostos orgânicos.

O estudo propõe o uso da macrófita aquática Salvinia cucullata como bioadsorvente para a remoção do corante
Laranja Ácido 7, corante este comumente empregado na indústria têxtil para tingimento de fibras de algodão e lã.

\section{MATERIAIS E MÉTODOS}

\section{Materiais}

A macrófita aquática Salvinia cucullata foi utilizada como bioadsorvente de corante neste estudo. A biomassa foi fornecida pelo curso de Engenharia de Pesca da Universidade Estadual do Oeste do Paraná. A macrófita Salvinia cucullata coletada foi lavada com água destilada várias vezes para a remoção de partículas de sujidade. Em seguida, a biomassa foi seca, moída e passada em um conjunto de peneiras a fim de ser utilizada nos ensaios de bioadsorção do corante com granulometria média de $0,75 \mathrm{~mm}$.

O corante sintético Laranja Ácido 7 (CI 15510, Orange II Sodium Salt, PM - 350,33 $\lambda_{\text {máx }}-437 \mathrm{~nm}$ ) foi obtido pela Sigma-Aldrich Ltda. Soluções sintéticas "mãe" do corante de $1000 \mathrm{mg} . \mathrm{L}^{-1}$ foram preparadas dissolvendo-se uma quantidade específica de corante em 1 litro de água deionizada. Em seguida, foram realizadas as diluições necessárias para a obtenção de soluções com valores de concentração na faixa de 20 a $300 \mathrm{mg} \cdot \mathrm{L}^{-1}$.

\section{Métodos}

Morfologia superficial: Foi realizado um estudo morfológico da biomassa através da Microscopia Óptica (MO), utilizando o microscópio óptico, da marca Leica e modelo DMLM (Alemanha). Também foi utilizada a técnica de Microscopia Eletrônica de Varredura (MEV), com o intuito de se obter imagens da superfície do material usando o microscópio óptico Suptter Coater, do fabricante BAL/TEC e modelo SCD 050.

Grupos funcionais: Para identificação dos grupos funcionais presentes na macrófita e ocorrência de modificações químicas na biomassa após a adsorção foram realizadas análises de espectroscopia na região do I.V. (FTIR) antes e depois do processo de bioadsorção.

Titulação potenciométrica: $\mathrm{O} \mathrm{pH}_{\mathrm{ZPC}}$ é o $\mathrm{pH}$ em que o adsorvente tem uma carga superficial líquida zero (Reed et al., 2000). Para valores de $\mathrm{pH}$ acima do $\mathrm{pH}_{\mathrm{ZPC}}$, a 
superfície adsorvente possui carga líquida negativa. Já para os casos em que o pH é inferior ao $\mathrm{pH}_{\mathrm{ZPC}}$, a superfície tem carga líquida positiva. A titulação potenciométrica foi realizada colocando-se em contato a biomassa com solução de acetato de amônio $\left(\mathrm{CH}_{3} \mathrm{COONH}_{4}[0,1 \mathrm{M}]\right)$, na concentração de 10 g. $\mathrm{L}^{-1}$, até o pH estabilizar. Dessa maneira, as amostras foram tituladas com ácido acético $\left(\mathrm{CH}_{3} \mathrm{COOH}\right) \quad(0,3 / 0,5 \mathrm{M})$ e hidróxido de amônio $\left(\mathrm{NH}_{4} \mathrm{OH}\right)(0,3 / 0,5 \mathrm{M})$.

Análises térmicas: Foi utilizada ainda a análise termogravimétrica (TGA) que mediu a variação de massa em função da temperatura. Além disso, foi realizada a calorimetria exploratória diferencial (DSC) que mediu as temperaturas e o fluxo de calor associado às transições de materiais em função do tempo e da temperatura. Os resultados de ambas as análises permitiram observar o comportamento e a estabilidade térmica dos materiais após a etapa de adsorção. As técnicas foram realizadas em equipamento da Shimadzu, modelo TGA-50 sob as condições de vazão de $\mathrm{N}_{2}$ de $50 \mathrm{~mL} / \mathrm{min}$, da temperatura ambiente a $1000{ }^{\circ} \mathrm{C}$ e razão de aquecimento de $10{ }^{\circ} \mathrm{C} / \mathrm{min}$.

\section{RESULTADOS E DISCUSSÃO}

\section{Morfologia superficial}

A Figura 1-a,b mostra as imagens obtidas por microscopia óptica (MO) da macrófita Salvinia cucullata antes e depois do processo de adsorção do corante Laranja Ácido 7, respectivamente. É perceptível a presença de alguns cristais na superfície da biomassa antes do processo de adsorção, que podem ser atribuídos à deposição de minerais. Após o processo de adsorção os cristais permaneceram na superfície do material. É interessante notar a alteração da cor na superfície da macrófita, que adquiriu tonalidades dos corantes utilizados no processo de adsorção. A Figura 2-a,b mostra as imagens obtidas através da microscopia eletrônica de varredura (MEV) da macrófita Salvinia cucullata antes e após a adsorção do corante Laranja Ácido 7, respectivamente.

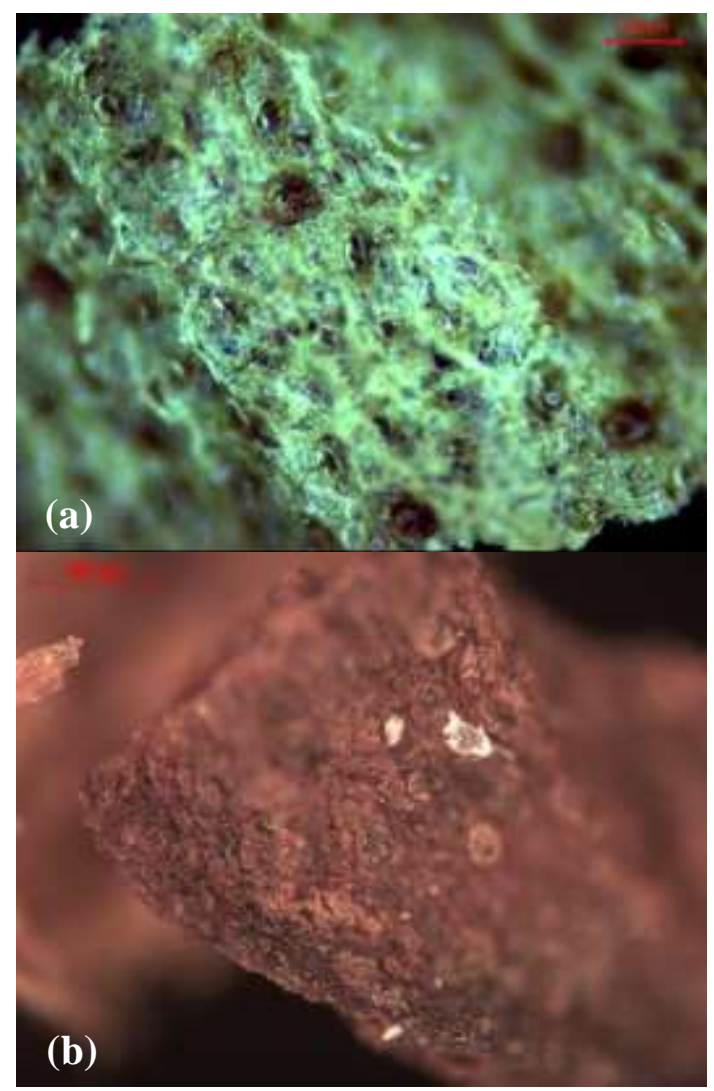

Figura 1 - MO da Salvinia cucullata (a) antes e (b) após processo de bioadsorção.

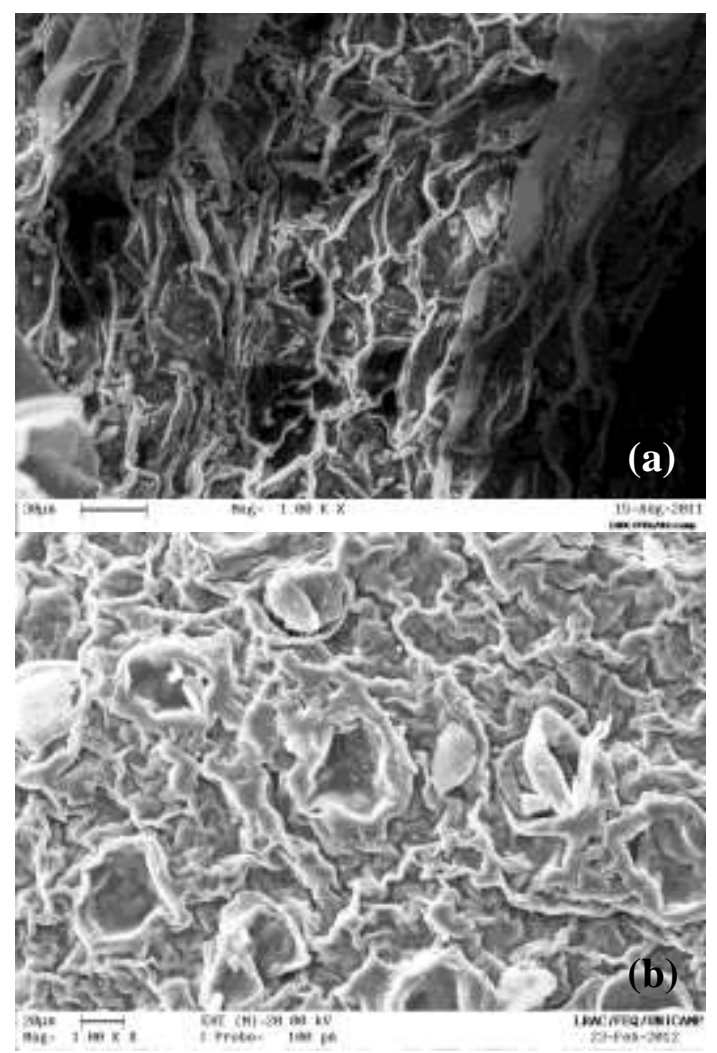

Figura 2 - MEV da Salvinia cucullata (a) antes e (b) após processo de bioadsorção.

Nessa análise, foi possível verificar a irregularidade da superfície da biomassa, além 
das estruturas identificadas como supostamente sendo cristais minerais. Pode ser visto que o corante não causou alterações estruturais significativas na superfície da macrófita, uma vez que a rugosidade mantevese aproximadamente a mesma, além das estruturas de cristal que não se alteraram.

\section{Grupos funcionais}

$\mathrm{Na}$ identificação dos grupos funcionais presentes na macrófita antes e após o processo de adsorção do corante Laranja Ácido 7, foi utilizado o espectro de infravermelho. Através da análise das bandas e dos picos formados (Figura 3) foi possível determinar as principais ligações químicas presentes nas amostras, bem como determinar os agrupamentos orgânicos mais predominantes. As mudanças nos grupos funcionais da macrófita antes do processo de adsorção e após adsorção do corante são apresentadas na Tabela 1. As bandas 2922$2849 \mathrm{~cm}^{-1}$ correspondem à vibração assimétrica e simétrica do metileno $\left(\mathrm{C}=\mathrm{H}_{2}\right)$, respectivamente. $\mathrm{O}$ pico em $1736 \mathrm{~cm}^{-1}$ corresponde a vibração do estiramento $\mathrm{C}=\mathrm{O}$ em aldeídos e foi observada tanto antes como após a adsorção do corante. Foi verificada a presença ligação $\mathrm{C}=\mathrm{C}$ de compostos orgânicos apenas na macrófita sem $\mathrm{o}$ corante, correspondente à banda $1408 \mathrm{~cm}^{-1}$.

A banda $1254 \mathrm{~cm}^{-1}$ pode ser atribuída ao estiramento $\mathrm{C}-\mathrm{O}$ de ácidos carboxílicos, e, apesar de estar presente tanto antes como após a adsorção, é mais evidente no segundo caso. O pico $908 \mathrm{~cm}^{-1}$ corresponde à deformação angular de alquenos e não foi observado após o processo de adsorção. Os picos na região de comprimento de onda de 900 a $690 \mathrm{~cm}^{-1}$ são atribuídos a anéis aromáticos e aos grupos haletos. A aparição e/ou não observação de picos e bandas na região do infravermelho após o processo de bioadsorção demonstra que, possivelmente, os grupos funcionais atribuídos aos respectivos comprimentos de onda participam diretamente do processo.
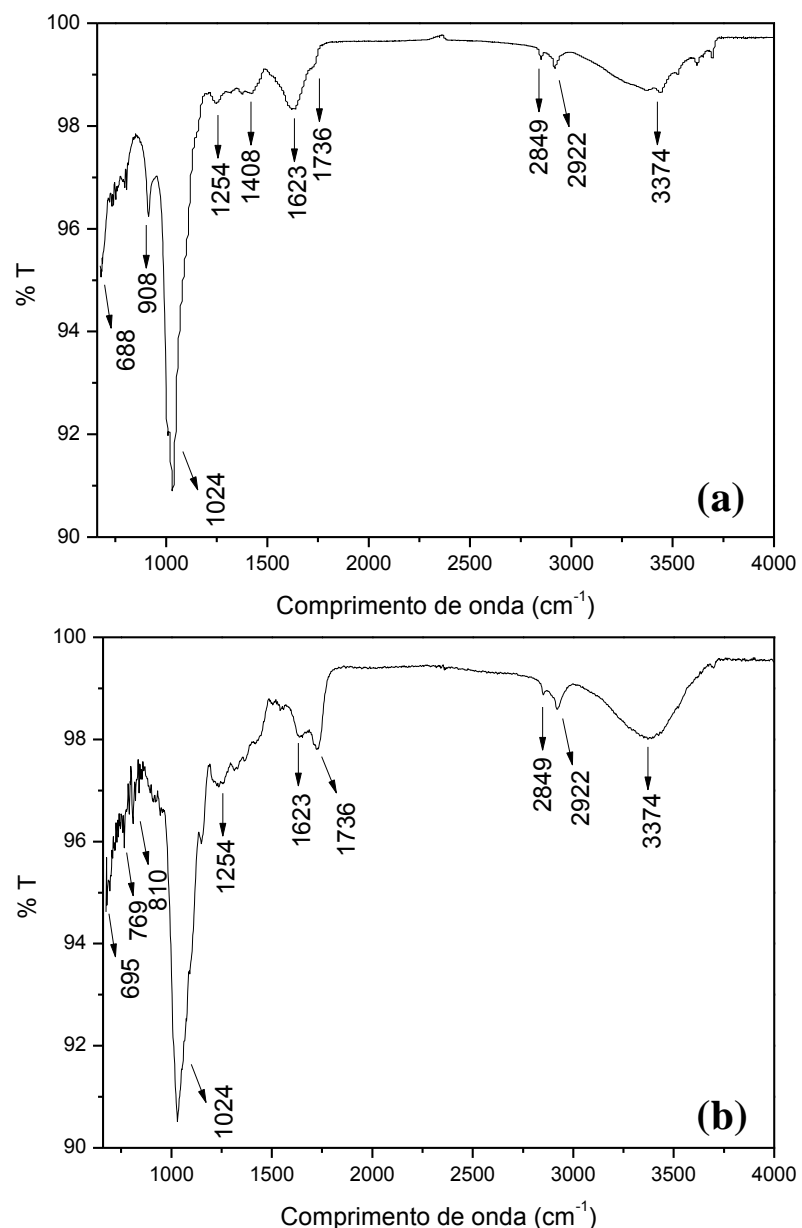

Figura 3 - Espectro de IV da Salvinia cucullata (a) antes e (b) após processo de bioadsorção.

Tabela 1 - Resumo dos grupos funcionais.

\begin{tabular}{lc|c}
\hline \multirow{2}{*}{ Grupos funcionais } & Antes & Após \\
\cline { 2 - 3 } & $\mathrm{cm}^{-1}$ & $\mathrm{~cm}^{-1}$ \\
\hline $\mathrm{O}=\mathrm{H}$ & 3374 & 3374 \\
Vibração C=H $\mathrm{H}_{2}$ & 2922 & 2922 \\
$\mathrm{C}=\mathrm{O}$ em aldeídos & 2849 & 2849 \\
Amida primária & 1736 & 1736 \\
$\mathrm{C}=\mathrm{C}$ em aromáticos & 1623 & 1623 \\
Estiramento C-O & 1408 & --- \\
Sulfóxido, S=O & 1254 & 1254 \\
RCH=CH & 1024 & 1024 \\
Anéis aromáticos & 908 & --- \\
Estiramento C-Cl & $900-690$ & $900-690$ \\
\hline
\end{tabular}

\section{Titulação potenciométrica}

$\mathrm{O} \mathrm{pH}_{\mathrm{ZPC}}$ é o $\mathrm{pH}$ em que o adsorvente tem uma carga superficial líquida zero (Reed et al., 2000). Para valores de $\mathrm{pH}$ acima do $\mathrm{pH}_{\mathrm{ZPC}}$, a superfície adsorvente possui carga líquida negativa. Já para os casos em que o pH 
é inferior ao $\mathrm{pH}_{\mathrm{ZPC}}$, a superfície tem carga líquida positiva. A titulação potenciométrica foi realizada colocando-se em contato a biomassa com solução de acetato de amônio $\left(\mathrm{CH}_{3} \mathrm{COONH}_{4}[0,1 \mathrm{M}]\right)$, na concentração de 10 g.L $\mathrm{L}^{-1}$, até o pH estabilizar. Dessa maneira, as amostras foram tituladas com ácido acético $\left(\mathrm{CH}_{3} \mathrm{COOH}\right)(0,3 \mathrm{M})$ e hidróxido de amônio $\left(\mathrm{NH}_{4} \mathrm{OH}\right)(0,3 \mathrm{M})$. Conforme a Figura 4, o $\mathrm{pH}$ cuja carga superficial da macrófita Salvinia cucullata é nula é igual a 5,7. Esse resultado é importante, pois é um fator determinante para que haja a interação iônica entre o bioadsorvente e o corante, propiciando ou prejudicando o processo de adsorção.

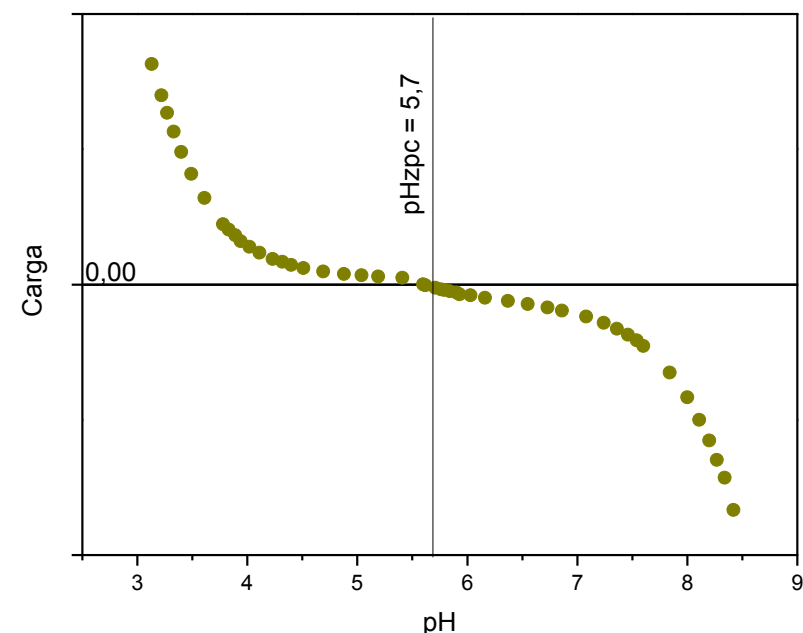

Figura $4-\mathrm{pH}_{\mathrm{ZPC}}$ da Salvinia cucullata.

\section{Análises térmicas}

A Figura 5 mostra a análise termogravimétrica da biomassa. Nela, foi possível estabelecer a perda mássica em função da temperatura e dividi-la em três etapas, de acordo com os principais máximos e mínimos da derivada da curva da perda de massa. Os motivos para que ocorra a perda de massa devem-se, entre outros fatores, à dessorção de gases e vapores, vaporização de líquidos, desidratação, decomposições químicas e sublimação de sólidos (Chen e McKeever, 1997).

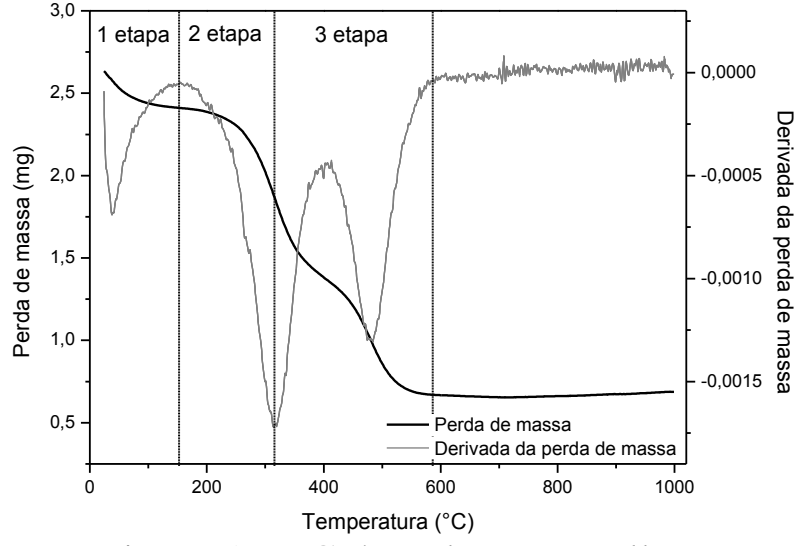

Figura 5-TG da Salvinia cucullata.

Com o auxílio do gráfico, determinouse a perda de massa total da macrófita, que foi de $73,91 \%$. A Tabela 2 mostra as porcentagens de perda de massa para cada uma as três etapas, bem como as explicações para cada uma dessas perdas.

Tabela 2 - Resumo das perdas mássicas nas diferentes etapas da análise térmica.

\begin{tabular}{|c|c|c|c|}
\hline Etapa & $\begin{array}{c}\text { Temperaturas, } \\
{ }^{\circ} \mathrm{C}\end{array}$ & $\begin{array}{c}\text { Perda } \\
\text { mássica, } \\
\%\end{array}$ & Motivo \\
\hline $1^{\mathrm{a}}$ & $25-150$ & 8,45 & $\begin{array}{l}\text { Perda de água, } \\
\text { microorganismos } \\
\text { e matéria } \\
\text { orgânica. }\end{array}$ \\
\hline $2^{a}$ & $150-310$ & 23,14 & $\begin{array}{c}\text { Perda de } \\
\text { hidroxilas. }\end{array}$ \\
\hline $3^{a}$ & $310-580$ & 61,47 & Descarbonatação. \\
\hline
\end{tabular}

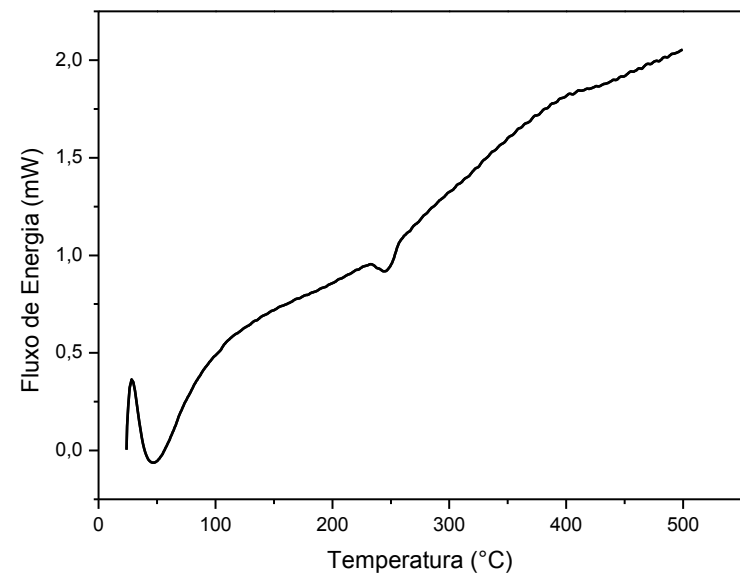

Figura 6 - DSC da Salvinia cucullata.

Na Figura 6 está representada a curva de calorimetria exploratória diferencial (DSC) da biomassa Salvinia cucullata. Observou-se que a macrófita teve dois principais eventos endotérmicos nas temperaturas de $50^{\circ} \mathrm{C}$ e 
$160^{\circ} \mathrm{C}$. O primeiro evento está associado à energia gasta para retirar as moléculas de água de hidratação da amostra. Já o segundo evento, provavelmente corresponde à energia associada à fusão da macrófita Salvinia cucullata.

\section{CONCLUSÕES}

O trabalho investigou a utilização da macrófita aquática Salvinia cucullata como bioadsorvente, na remoção do corante Ácido Laranja 7 visando compreender os possíveis mecanismos do processo de bioadsorção da macrófita pelo corante, e até onde as mudanças estruturais sofridas pela biomassa, após a bioadsorção, interferem nestes mecanismos. Por meio da análise morfológica através da MEV e da MO, percebeu-se que a biomassa não sofreu modificações estruturais devido à ação do corante após o processo de bioadsorção do mesmo. Já o estudo do $\mathrm{pH}_{\mathrm{ZPC}}$, permitiu restringir uma faixa de valores de pH's cuja bioadsorção se faz eficaz, devido às interações eletrostáticas entre a superfície da biomassa e do corante. Verificou-se um $\mathrm{pH}_{\mathrm{ZPC}}$ de 5,7 e uma descarbonatação do material a temperaturas superiores a $325^{\circ} \mathrm{C}$, representando $73,9 \%$ da perda mássica total. Quanto ao estudo dos grupos funcionais da biomassa, não foram verificadas alterações significativas em sua composição. Frente ao estudo, concluiu-se que a Salvinia cucullata constitui um potencial bioadsorvente para a remoção do corante Ácido Laranja 7, pois não apresentou alterações físicas e químicas significativas no que tange sua viabilidade na utilização como bioadsorvente.

\section{REFERÊNCIAS}

CAMARGO, A. F. M.; PEZZATO, M. M; HENRY-SILVA, G. G. (2003), Fatores limitantes ao crescimento de macrófitas aquáticas. In Thomaz, S. M. \& L. M. Bini (eds), Ecologia e Manejo de Macrófitas Aquáticas. Eduem, Maringá: 59-84.

CHEN, R.; MCKEEVER, S.W.S. (1997), Theory of Thermoluminescence and Related Phenomena, World Sci. Publishers, Singapore.
DA SILVA, G. L., SILVA, V. L., VIEIRA, M. G. A., SILVA, M. G. C. (2010), Solophenyl navy blue dye removal from smectite clay in porous bed column. Adsorption Science \& Technology 27, $861-875$.

FORGACS, E.; CSERHÁTI, T.; OROS, G. (2004), Removal of synthetic dyes from wastewaters: a review. Environ. Int., v. 30, p. 953-971.

GUARATINI, C.C.I.; ZANONI, M.V.B. (2000), Corantes têxteis, Revista Química Nova, v. 23, n.1, p. 71-78.

REED, B.E.; VAUGHAN, R.; JIANG, L. (2000), As(III), As(V), $\mathrm{Hg}$, and $\mathrm{Pb}$ removal by Fe-oxide impregnated activated carbon, Journal of Environmental Engineering, v. 126, n. 9, p. $869-873$.

ROBINSON, T.; MCMULLAN, G.; MARCHANT, R.; NIGAM, P. (2001), Remediation of dyes in textile effluent: a critical review on current treatment technologies with a proposed alternative. Biores. Technol. v. 77, p. 247-255.

SEPÚlVEDA, L. A., SANTANA, C. C. (2010), Adsorção de naftol azul preto em turfa: estudos cinéticos e curvas de ruptura. Anais do XVIII COBEQ 2010, Foz do Iguaçu-Brasil, 4711 - 4720.

SIVARAJ.R.; NAMASIVAYAM. C.; KADIRVELU, K. (2001), Orange peel as an adsorbent in the removal of acid violet 17 (acid dye) from aqueous solutions, Waste Management, v. 21, p. 105-110.

TUBIAKI, B. T., BOMBARDELLI, R. A. E SILVA, E. A. (2010), Estudo da remoção do corante azul $5 \mathrm{~g}$ pelo processo de biossorção empregrando macrófitas. Anais do XVIII COBEQ 2010, Foz do IguaçuBrasil, 1781 - 1789.

ZOLLINGER, H. (2003), Color chemistry: syntheses, properties, and applications of organic dyes and pigments. 3 ed. Zurich: Wiley.

\section{AGRADECIMENTOS}

Os autores agradecem à FAPESP pelo apoio financeiro. 